CHALMERS

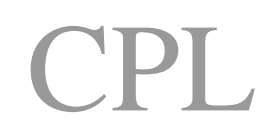

Chalmers Publication Library

Institutional Repository of

Chalmers University of Technology

http://publications.lib. chalmers.se

Copyright notice (post print) Taylor \& Francis

This is an electronic version of an article published in International Journal of Crashworthiness.

http://dx.doi.org/10.1080/13588265.2011.648514 


\title{
Truck Frontal Underride Protection - Compatibility Factors Influencing Passenger Car Safety
}

\author{
Aleksandra Krusper \\ Department of Applied Mechanics, Chalmers University of Technology, Gothenburg, \\ Sweden \\ Robert Thomson \\ Swedish National Road and Transport research Institute (VTI), Gothenburg Sweden \\ Aleksandra Krusper \\ P.O.Box 8077
}

SE-402 78 Gothenburg, Sweden

Tel.: +46(0)31 7723652

Fax: +46(0)317647188

E-mail: aleksandra.krusper@chalmers.se 


\title{
Truck Frontal Underride Protection - Compatibility Factors Influencing Passenger Car Safety
}

\begin{abstract}
Frontal collisions between passenger cars and trucks are the most severe vehiclevehicle collisions observed in accident statistics. Regulation 93 was developed to reduce the risk of fatal injury by preventing passenger cars from underriding heavy truck structures. The regulation does not fully address the higher energy of content in these collisions where passenger car structures cannot be expected to have sufficient energy absorbing capacity. The performance of a FUPD incorporated into a FE truck model was evaluated and compared to earlier studies by the authors. In particular, structural interaction of the car with the truck structures was investigated. The packing of the FUPD and truck structures was a critical factor for the FUPD performance. It was found that when the vertical offset between the FUPD truck frame rails is too small, the efficiency of the FUPD is decreased. Incorporating deformable truck frame elements is only beneficial if the offset is at least $220 \mathrm{~mm}$.
\end{abstract}

Keywords: frontal crash, front underrun protective device; compatibility, heavy goods vehicles, FEM

\section{Introduction}

Frontal collisions between passenger cars and Heavy Goods Vehicles (HGV) are the most severe vehicle-vehicle collisions observed in accident statistics (Rechnitzer 1993; NHTSA 1998; Schäfer et al. 1999). The reason can be attributed to the great difference between the structure and mass (and thereby stiffness) of the two types of vehicles. Directive 2000/40/EC was developed to reduce the risk of fatal injury by preventing passenger cars from underriding truck structures and thereby reducing the severity of the frontal crashes. The directive demands that all trucks produced after 
August 2003 are equipped with a Front Underrun Protective Device (FUPD) obeying requirements given by Economic Commission for Europe Regulation No. 93 (ECER93). Although this countermeasure can improve the interaction between the vehicles, the regulation does not fully address the higher energy content in these collisions where passenger car structure cannot be expected to have sufficient energy absorbing capacity. The Regulation has been criticized for specifying low stiffness requirements for the FUPD. The problem of insufficient bending stiffness of FUPD beam has also been reported in in-depth car to truck accidents analysis (Krusper and Thomson 2008). A statistical accident analysis has shown that closing speeds for fatal injuries are generally above $80 \mathrm{~km} / \mathrm{h}$ (Schram et al. 2006). For reference, passenger car frontal protection in ECE Regulation 94 was based on closing speeds of $100 \mathrm{~km} / \mathrm{h}$ (EEVC 1996). The accident analysis in VC-COMPAT showed that more collisions occur for horizontal overlaps where less than $50 \%$ of a truck and $75 \%$ of a vehicle fronts are involved (Gwehenberger 2003) and is in agreement with another accident investigation (EEVC WG 14 1996) where horizontal overlap of $75 \%$ and $75 \mathrm{~km} / \mathrm{h}$ closing speed was found as a typical crash configuration. Closing speeds above $80 \mathrm{~km} / \mathrm{h}$ were found as the limit speed after which fatalities begin to be noticeable in the data. Fatal accidents represent $50 \%$ of accidents with closing speeds around $130 \mathrm{~km} / \mathrm{h}$ (Gwehenberger et al. 2003). The greatest proportion of impacts lies in the 12 o'clock $(+/-15 \mathrm{deg})$ category with impacts of larger angles being less common. It is important to note that closing speeds of 100 $\mathrm{km} / \mathrm{h}$ are easily achieved in urban traffic. Already in 1993 energy absorbing FUPD has been proposed as a further step in improving passenger car's occupant protection (Rechnitzer 1993).

Although some car to truck tests with energy absorbing FUPD have been performed either sufficient data to evaluate e.a. FUPD were not given (Forsman 2002) 
or the energy absorbing parts of FUPD were not triggered. However, all tests were run with $75 \%$ horizontal overlap and $100 \%$ vertical overlap. The only test where an e.a. FUPD showed desired performance was done within VC-COMPAT project with specially designed FUPD. A crash configuration for this test was planned in the way which did not allow contact between stiff parts of the passenger car (engine and gear box) and corresponding truck stiff structures resulting in $110 \mathrm{~mm}$ FUPD protrusion outside of truck's front and $400 \mathrm{~mm}$ of its gross rearward displacement. Horizontal and vertical overlaps were $72 \%$ and $100 \%$ respectively. Although one of the trucks considered in the in-depth accident analysis (Krusper and Thomson 2008) was equipped with e.a. FUPD, its performance could not be analyzed. MADYMO models (EEVC WG14) were used to simulate car-truck impact with e.a. FUPD with closing speeds of 56, 75 and $90 \mathrm{kmh}^{-1}$. Deformation distances for FUPD were 50, 160, 360 and $480 \mathrm{~mm}$ with $200 \mathrm{kN}$ crush triggering force and $400-600 \mathrm{kN}$ maximum force. Horizontal and vertical overlaps were $75 \%$ and $100 \%$ respectively for all simulations. Based on forces and deformations registered on dummies (no intrusions could be simulated) it was found that the optimal deformation length for the FUPD is around $360 \mathrm{~mm}$. Another two sets of car - truck crash simulations based on FEM (Finite Element Method) were run within the VC-Compat project (Schram 2005 D14). The closing speeds of 56, 75 and $90 \mathrm{~km}^{-1}$ were combined with 50, 75 and $100 \%$ horizontal overlaps under full vertical overlap. In the first set of simulations four trucks were used for each combination: one model represented the trucks currently on the roads and three other models which some stiff parts were removed on the front. The other set of simulations considered two trucks: original with statutory rigid FUPD and one with e.a. FUPD. The triggering force for the e.a FUPD was $0 \mathrm{kN}$ for both sets of simulation. The resistance force linearly increased until it reached a specified force (for $100 \mathrm{~mm}$ deformation) and then it was kept 
constant (plateau). All the models in the first set included e.a FUPD with plateau force of $200 \mathrm{kN}$. The e.a. FUPD in the second test had a plateau force of $250 \mathrm{kN}$. The conclusion was that the most benefit of using e.a. FUPD was found to be for $75 \%$ horizontal overlap especially when the steering unit and towing hooks were not present in the truck front.

An in-depth accident analysis (Krusper and Thomson 2008) showed that the FUPD height could be sensitive to the truck load and a taller FUPD could compensate for vertical variations. A more critical observation was that FUPD cross-beams may be both positioned too low and/or insufficiently stiff to limit cars underriding trucks even when with rigid FUPDs.

From accident and structural analysis of trucks and passenger cars (Krusper and Thomson 2008) it was seen that the vertical overlaps between longitudinals and FUPDs varies. The placement of the FUPD relative to the other truck's parts depends primarily on ground the clearance of a truck's frame which depends on purpose of the truck and placement of its other structural parts. Since, passenger cars are more sensitive to vertical than to horizontal overlaps (Thomson et. al.) these differences cannot be neglected in study of e.a. FUPD performance. Also, the activation force and energy absorption capacity of these systems needed to be further evaluated.

The goal of this study is to extend the previous research and identify the total system performance of the HGV and e.a. FUPD and provide insight into issues relevant for heavy truck design. The study is based on and is continuation of a studies on e.a. FUPDs: accident and structural analysis (Krusper and Thomson 2008) which identified the problems related to FUPDs; investigation of e.a FUPDs theoretical possibilities to absorb energy when interacting with cars under different vertical and horizontal overlaps (Krusper and Thomson 2010); and then comparison was made between the 
performance of e.a. FUPDs with $120 \mathrm{~mm}$ and $240 \mathrm{~mm}$ front surface (Krusper and Thomson 2010).

The performance of e.a. FUPDs of two different heights in interaction with passenger car was investigated when it is installed on truck and not completely free to deform due to its additional interaction with truck. It was found that performance of FUPD is decreased from its theoretical possibilities due to interactions with truck front and passenger car. When the vertical offset between the FUPD and truck frame rails is too small the efficiency of the FUPD is further decreased. Incorporating deformable truck frame elements is only beneficial if the vertical offset between the FUPD and truck frame rails is at least $220 \mathrm{~mm}$. On the other hand stiff truck frame rails have more influence on FUPD performance under different vertical overlaps than the deformable ones.

\section{Methodology}

To complement the previous study of the idealized impact of a car and an e.a. FUPD, the total truck and FUPD structure was simulated with impacts of passenger cars. Similar to the previous study, different collision configurations were studied to see how the striking car interacts with the stiffer components of the truck. The results from the previous studies were used to evaluate the difference in e.a. FUPD efficiency between the situation when the truck was not present and when the e.a. FUPD is integrated into truck so both the passenger car and FUPD interact with stiffer parts of the truck. The model of an e.a. FUPD used in the previous study showed good performance with interaction with passenger car. Therefore, eventual poor performance of the FUPD in interaction with passenger car and truck structures can only be a result of additional interactions with truck structures. 
The main parameters investigated in this series were: vertical and horizontal alignment of the car and FUPD when it is installed on the truck, vertical distance between the FUPD and rigid truck frame, vertical height (cross-section) of the FUPD, and the influence of deformable truck rails. Part of the simulation series were intended to investigate effects of both impact speed and vehicle mass, but also the energy absorbing element's force levels. Impact speeds of $75 \mathrm{~km} / \mathrm{h}$ were studied for a mid size (Ford Taurus). A smaller $900 \mathrm{~kg}$ (Geo Metro), and a $1330 \mathrm{~kg}$ car (Dodge Neon) were used at $56 \mathrm{~km} / \mathrm{h}$. These models exhibited weak compartments and were not used for higher impact speeds. They were used to investigate an FUPD activation forces for light vehicles.

\section{Models}

All simulations were performed using LS-Dyna (Livermore 2007). Three types of finite element (FE) models were used: passenger cars, e.a. FUPD, and a simplified truck model. In the simulations, the passenger car was the bullet vehicle while the truck was stationary. The ends of e.a. elements of the FUPD are fixed to the front of the truck under its frame rails and they do not move relative to the truck.

The model of the passenger cars are the NCAC derived Taurus, GEO Metro and Dodge Neon models. The Taurus NCAC (2007) model of a 2001 Ford Taurus is somewhat modified to make it more representative of a European car in crash performance against Full Width Rigid Barrier (FWRB) and simplified to decrease calculation time (Thomson et al. 2008). As a reference for modifications, results of impact against rigid barrier for 22 European vehicles performed at NHTSA (National Highway Traffic Safety Administration) were used (Figure 1). The model has been used in the most of simulations for investigation of e.a. FUPD performance. Both the NCAC derived GEO Metro and Dodge Neon models were used to simulate smaller vehicles 
impacting the FUPD. These models represent dated (1990's) vehicle designs and were not used to study detailed vehicle response. All car models are shown by Figure 2. Their main longitudinals are highlighted.

The models of the e.a. FUPDs are those used in the previous study (Krusper and Thomson 2010, 2010). The e.a. FUPD model is shown in Figure 3a. The e.a. elements are modeled as springs with 6 degrees of freedom. The spring model has advantages over a real model of FUPD since performance of a real FUPD is limited by its design. The practical example is standard e.a. FUPD used in one of VC-Compat tests which energy absorbing elements were not triggered in the test. The model with spring elements allowed easy setting of triggering force and maximum deformation length. Also, it was easy to tune the force/moment vs displacement/rotation characteristics to 75 $\mathrm{kmh}^{-1}$ impact speed and assure some energy absorption by the FUPD for all three horizontal overlaps. The axial triggering force was set to $160 \mathrm{kN}$ (Figure 3b). All forces and moments characteristics are set to linearly increase until reaching a specified value thereafter it remains constant to assure stable deformation of the car hitting the FUPD (Schram et al. 2006). Available deformation distance (displacement) has been chosen to be $300 \mathrm{~mm}$. This displacement corresponds to available space between the front surface of the truck frame and near front suspension mounts measured on three newer trucks listed in the VC-Compat structural database. The vertical size of the FUPD cross beam was varied between 120 to $240 \mathrm{~mm}$. The FUPD crossbeam bending strength was adapted to the dimensions so that the same deformation would be achieved for an identical point load dynamically applied to the FUPD end for both 120 and $240 \mathrm{~mm}$ FUPDS (Krusper and Thomson 2010). The mass of the crossbeams were normalized to eliminate any inertial effects between the simulation cases. Material properties for the FUPD beam model were taken from existing Volvo e.a. FUPD beam. 
Figure 4 shows the truck model with frame, radiator components, and incorporated e.a. FUPD. The model includes truck components seen in tests performed by Working Group 14 in EEVC (EEVC WG 14 1996). The dimensions for truck rails were taken from VC- Compat truck database. The model for radiator components is based on SCANIA truck models. All other parts under the radiator components were not necessary to model since the stiff FUPD beam does not allow passenger car to travel further than the e.a. elements supports, i.e, in this case, front suspensions. The forward elements of the truck model are deformable except the transparent section of the main frame. This section was varied between rigid (effective stiffness of truck rail) and deformable (proposed modification).

\section{Simulations}

All vertical alignments are measured between the car longitudinals and the $120 \mathrm{~mm}$ e.a. FUPD (smallest) cross-section and expressed as a percentage relative to the passenger car longitudinals. The vertical offsets between the truck frame rails and FUPD refer to the distance between the FUPD centerline and the lower surface of the truck frame rail. Therefore, different vertical sizes of the cross-beams give different sizes of the contact area between the car and FUPD but also between the truck cooler and FUPD crossbeam. The vertical size of the cross-beam influences also the clearance between the upper surface of the cross-beam and lower surface of the truck frame rails. Vertical alignments were varied from full overlap to $50 \%$ percent overlap where two positions of the FUPD were considered: higher and lower relative to car longitudinals. When changing vertical overlap, the whole truck structure with FUPD was moved relative to the car. For the horizontal overlap, three positions were considered in the simulations: full overlap, $75 \%$ and $50 \%$ relative to the car front end. Finally two stiffnesses of the front part of the truck rails were investigated: rigid and deformable (same material 
properties as car longitudinals).

A Geo Metro model was run against the truck model for speeds of 56 and 75 $\mathrm{km} / \mathrm{h}$ with horizontal overlap of $75 \%$ and full vertical overlap. A Dodge Neon model was also run against truck with an impact speed of $56 \mathrm{~km} / \mathrm{h}, 50 \%$ horizontal overlap and full vertical overlap.

Simulations performed are given by Tables 1, 2, and 3 together with the previously performed simulations (Krusper and Thomson 2010, 2010) where the Taurus model was run against an e.a. FUPD mounted independent of the truck.

\section{Output Parameters}

Since a model of the dummy was not included in the simulations, the intrusions into the occupant compartment and car accelerations were used as the indicator of severity (Delannoy et al. 2005, Thomas 2005). The points on the firewall where the intrusions were measured on the Taurus model (passenger car in further text) are shown in Figure 5.

The points on the two upper rows were considered to belong to the dashboard while the remaining points refer to the footwell area of the firewall. Other output parameters were mostly used to clarify and understand the crash interaction and performance of the component models. For the latter purpose, ride down distance, forces and moments at e.a. deformable elements, amount of energy absorbed by the car, e.a. FUPD and truck, residual, sliding energy and hourglass energy are used.

\section{Results}

The amount of hourglass energy developed during the simulations (around 1.3\% - less than $6 \%$ of the total energy) and examination of the balance of system energy 
components showed that all simulations performed are reliable (Consolazio et al. 2003). The glstat data from two simulations are given in Figure 6.

The influence of the truck architecture on e.a. FUPD performance was investigated by comparing the results from passenger car -to-e.a. FUPD simulations with passenger car -to-rigid frame truck simulations. Figure 7 shows how the deformation patterns of the passenger car changes between the idealized case of the car to FWRB, car-e.a. FUPD, and car-e.a. FUPD when it is included in the truck frame. The sill buckled in all three cases but the deformation was most severe for the car-FWRB impact. An e.a. FUPD offers additional energy absorbing components than the FWRB but Figure 7 shows there is a much smaller interaction surface, with or without the truck frame, when compared to a car-FWRB impact. The least deformation was found for carFUPD impact when the e.a. FUPD could deform freely. Severe deformations were registered for car- rigid truck frame impacts but they were smaller than in the case of the car-FWRB impact. The efficiency of the e.a. FUPD was seen to decrease due to car interactions with truck structurs and also interactions between the truck cooler and FUPD.

Intrusions for the car-to-FUPD are compared to the intrusions for the close FUPD/frame placement in a HGV (frame - FUPD offset of $160 \mathrm{~mm}$ ) (Figure 8). All intrusions are normalized to the average intrusion of the entire firewall for the car-toFWRB impact simulations. A distinction is made between intrusions registered at dashboard and footwell. In general for FUPD impacts, the intrusions at the dashboard are higher than those registered at the firewall while the opposite occurs for the car-toFWRB impacts.

The intrusions for car-to-rigid frame truck impacts (right side of Figure 8) are higher than those registered for car-to-FUPD impacts (left side of Figure 8). While an 
isolated FUPD of $240 \mathrm{~mm}$ (larger FUPD - black lines) shows better performance for car-to-FUPD compared to a $120 \mathrm{~mm}$ FUPD (smaller FUPD - grey lines), this advantage is less obvious or disappears when the rigid frame rails are closely placed to the FUPD. For the same vertical overlap and different horizontal overlaps there is more variation in intrusions when the truck is present. Also intrusions are increasing with smaller horizontal overlap. As shown in Figure 6, the rigid frame rails contact the upper front structures of the car and limit the stroke of the e.a. FUPD. The combination of these actions results in higher intrusions as more energy must be absorbed by the car than in the FUPD case only.

The intrusions at the car dashboard for car-to-FUPD impact when a FUPD of $120 \mathrm{~mm}$ is placed higher exceed intrusions registered for car-to-FWRB impact in Figure 8. This is an overriding position of the FUPD and is the worst loading case for the car. It is also expected that higher intrusions will be registered for car-to-rigid frame truck when a FUPD is placed higher, relative to the car, regardless of its cross-beam height since the upper part of car front is loaded not only by FUPD but also by stiffer truck structures. Inspection of the simulations confirmed that the truck parts partly prevent backward movement of the FUPD cross beam and therefore limits full deformation of e.a. elements.

It was noticed in previous studies that the bending of the idealized FUPD crossbeam for lower horizontal overlaps allows rotation of the car which limits deformations of the car (Krusper and Thomson 2010). Some of the original impact energy remains in the post impact kinetic energy and is not directed into structural deformation energy. The reduced deformation of the FUPD cross-beam for car-to-rigid frame truck is also prevented by the stiffer truck parts and the car continues to translate instead of rotating, resulting in more car deformations. 
Acceleration vs. displacement curves (Figure 9) are similar for car-to-FUPD and car-to-rigid frame truck when a FUPD of $120 \mathrm{~mm}$ is used. Somewhat earlier but higher acceleration peaks can be seen for car-to-rigid frame truck cases since the hard truck parts deforms higher parts of the car front and partially softens the impact when deformation of e.a. elements stopped. The acceleration peaks for the car-rigid frame truck correspond to the moment when the car impacts the truck's rigid frame elements while the acceleration peak for the car-FUPD impact occur when the forces in e.a. elements reach their maximum and the car front end stops deforming. There is no significant difference in acceleration vs displacement curves for the FUPDs.

A distribution of absorbed energy for these cases is shown by Figure 10. When the truck structure is present, the energy absorbed by a FUPD decreases from 30 to $14 \%$ and from 32 to $12 \%$ for FUPD sizes of 120 and $240 \mathrm{~mm}$ respectively.

The influence of the stiffness of truck frame rails and the distance between FUPD centerline and truck frame's lower surface on intrusions of the car firewall is shown by Figures 11 (rigid frames rails) and Figure 12 (deformable frame rails). The reference intrusion in all cases is the FWRB load case. Even for deformable truck rails, intrusions are higher for the dashboard than for the footwell. Three distances between the centerline of the FUPD and the lower surface of the truck frame rails are presented: 160, 220 and $280 \mathrm{~mm}$. Regardless of the distance between the centerline of the e.a. FUPD and the lower surface of the truck frame rails, less intrusions were registered when the car was run against truck with deformable rails for the same crash configuration. On the other hand, regardless the stiffness of the frame, the worst results are obtained for close FUPD/frame placement (frame - FUPD offset of 160 $\mathrm{mm})$. 
An e.a. FUPD exhibits the best performance for full horizontal overlap. The intrusions for both, 75 and 100\% horizontal overlaps, are less when the FUPD of 240 $\mathrm{mm}$ is used but it is not always the case for $50 \%$ overlap.

When the FUPD is placed lower or fully overlaps vertically with the car longitudinals, the deformable frame causes less intrusion. Even for smaller overlaps and higher placed truck frame (offset $280 \mathrm{~mm}$ ), the intrusions are higher than in the idealized case, i.e. when the truck is not present (Figure 13, left). The acceleration vs displacement curve shows a very sharp peak at the end for the case when only the FUPD interacts with the car (Figure 13, right). It corresponds to the impact with FUPD supports. This impact is not present in car-to-truck cases.

The advantage of having a deformable frame is also visible for the offset of 220 $\mathrm{mm}$. The center figures in Figure 12 (deformable frame) can be compared to those in Figure 11 (rigid frame). Here, a smaller offset caused more overlap between the car and the truck cooler as well as the deformable truck frame. The higher overlap was sufficient to deform the frame and cooler. The deformation gave space for FUPD deformation allowing e.a. elements to deform further. When looking at acceleration vs displacement curves for the simulated cases (Figures 14 and 15), it can be seen that here the advantage of having deformable truck frame rails is highest for $75 \%$ horizontal overlap but still depends on the offset.

Figure 16 shows that energy absorption is more influenced by the stiffness of truck frame rails in the case of higher FUPD. The difference in energies absorbed by the car and FUPD is relatively high for impact into truck with deformable rails and for the two different heights of FUPDs. Intrusions differences for the rigid truck rails are not so obvious (Figure 12). Acceleration vs displacement curves show differences in the 
acceleration values for the two cases. The acceleration is higher for smaller FUPD and implies higher impact force.

Figure 17 and 18 shows that energy absorption is less influenced by the offset for deformable truck frame rails and FUPD of $240 \mathrm{~mm}$ than for the same cases but with rigid truck frames. Also for the cases with rigid truck frame, the difference in energy absorption is less if FUPD of $120 \mathrm{~mm}$ is used. The lowest amount of energy absorbed by the FUPD is around $38 \mathrm{~kJ}$ and refers to higher FUPD, 75\% horizontal overlap and rigid truck frame rails with offset of $160 \mathrm{~mm}$. The highest value registered is $97 \mathrm{~kJ}$ and refers also to a larger FUPD, but deformable truck frame rails, 50\% horizontal and 50\% vertical overlap and lower placed FUPD relative to car longitudinals.

Finally, maximum force and moments resultants registered are found for different cases. The maximum force in the axial direction of e.a. element has reached the maximum possible resistant force of the e.a. elements (Figure 4), while forces in other directions and moments are under the highest values specified for the elements. Still the displacements of the free end of the e.a. elements in lateral and vertical directions are relatively small.

A concern for the FUP designs was that the activation force and subsequent force-deflection curve for the FUPD may be too high for a smaller vehicle. As seen in Figure 12, the forces of car-barrier and car-FUP impacts lie in the same corridor up to $20 \mathrm{~ms}$ when the load reaches $200 \mathrm{kN}$. The Ford Taurus - FWRB data is also plotted for reference.

The Geo Metro and Dodge Neon showed maximum wall loads of $500 \mathrm{kN}$ in the FWRB configuration at $56 \mathrm{~km} / \mathrm{h}$. The rigid wall impacts at $56 \mathrm{~km} / \mathrm{h}$ are plotted on the same figure as the car to HGV and FUPD impacts. Both small vehicles began to exhibit compartment deformations at around $20 \mathrm{~ms}$ in this case and are about $250 \mathrm{kN}$ in the 
FWRB case. Although their peak forces exceeded $450 \mathrm{kN}$, the compartment was not stable enough for a $75 \mathrm{~km} / \mathrm{h}$ impact.

The FUP springs were activated in all the simulations with lighter vehicles and were compressed to at least $2 / 3$ of their original length indicating that the all masses of the simulated vehicle were able to activate and deform the FUPD. At $56 \mathrm{~km} / \mathrm{h}$, compartment deformations were acceptable but this was not the case for higher speeds. For reference, the Taurus exhibited initial signs of compartment deformation in a FWRB when the wall forces were estimated at $650 \mathrm{kN}$ (Figure 19).

\section{Discussion}

From the previous study it was found that the stiffness of the e.a. FUPD cross-beam and the axial triggering force of the e.a. elements and vertical height of the cross-beam cross section are the factors influencing efficiency of the e.a. FUPD. The research was based on the impact simulations between car and e.a. FUPD. Since, the FUPD beam interacts directly with passenger car front structures, stiff beams are able to transfer impact force to energy absorbing elements and at the same time keeps the contact surface spread over the car front preventing a fork effect. Also, It was shown that FUPD with higher beam cross section provides better structural interaction with the car, resulting in higher energy absorption by the FUPD. The energy absorbed by the FUPD for all cases varied from 65 to $115 \mathrm{~kJ}$ depending on vertical and horizontal overlap but also on height of front beam surface. After finding an adequate stiffness, and triggering force, e.a. absorbing FUPD of two cross-beam cross-section heights were found less severe to the impacting car than FWRB. It shows that the energy absorbed by the e.a. FUPD influenced the impact in more positive way than the reduction of the contact surface influenced it in negative way. In all cases there was a trend of intrusion reduction as 
horizontal overlap decreased under $75 \%$ implying that e.a. FUPD makes car crash more predictable in comparison to car to car crashes (Thomson et al., 2008). When the car impacts e.a. FUPD the intrusions are always higher at the dashboard than at the footwell while the opposite stands for the impact against FWRB. The FWRB forces deformation of the whole car front while e.a. FUPD interacts directly almost only with longitudinals of the car. The result is that the longitudinal bends up and pushes the dashboard on reward. This is most obvious for the case when the FUPD is placed higher relative to the longitudinal. However, intrusions at the car firewall were always less after the car impacted the e.a. FUPD than after impact with the FWRB. Only when the smaller FUPD was placed higher than the longituinals and for $75 \%$ and $50 \%$ horizontal overlap did the intrusions at the dashboard exceeded the intrusions registered for the impact against FWRB. Therefore, the model chosen for e.a. FUPD can be considered efficient in reducing the severity of frontal crashes with passenger cars. But that was an idealized case where the e.a. elements of the FUPD could deform freely and its efficiency depended only on its structural interaction with passenger car. The question is if it is possible to keep the same ability of e.a. FUPD to absorb the energy even when it is installed at the truck and how the ability varies depending on FUPD placement at the truck relative to car's longitudinals and truck's rails.

When integrated into truck a structure, the e.a. FUPD interacts not only with passenger car front but also with the truck structure. The contact area between the car front and its target is increased but the truck structure restricted the deformation of the FUPD e.a. elements. In the car-truck simulations the offset between the truck frame rails and FUPD was varied. These offsets were combined with different vertical and horizontal overlaps between the car longitudinals and the FUPD. Also FUPD with higher and smaller cross-beam cross sections were used and two different stiffnesses of 
the truck rails were considered. Since, the higher placed e.a. FUPD does not give desirable results even for the idealized case it has been concluded that the higher placed FUPD together with truck frame rails will cause even worse results. Therefore, less attention is paid on these cases and only few simulations were run with higher placed FUPD.

In general, an e.a. FUPD performed better when the truck structures were not present since the e.a. elements could deform freely. The truck structure interacted with the car and the FUPD contacted the truck cooling system and frame rails. Depending on the offset between the FUPD centerline and lower surface of the truck frame, different portions of the FUPD and truck cooling system overlapped. In some cases this overlap facilitated deformation of the truck frame and radiator (case of offset $220 \mathrm{~mm}$ ). The deformable frame allowed rearward movement of the radiator but also took up some energy through deformations. The energy absorbed by the truck was small in all cases (up to $6 \mathrm{~kJ}$ ) for deformable truck frame but the energy absorbed by the FUPD was much higher when compared to cases with rigid truck frame. It can be concluded that the ability of deformable truck frame rails to take up energy is of less importance than the fact that a deformable frame allows further backward movement of the FUPD. However, the energy absorbing capabilities of FUPD could not be fully used. The reduction in FUPD energy dissipation is accompanied by a corresponding increase in energy absorbed by the car in both cases. Deformation of the higher FUPD is more restricted by contact with the truck structure since it builds a larger contact area with truck cooler. As a result it influences the amount of energy needed to be absorbed by the car making larger differences in energy absorbed by the car and higher FUPD than energy absorbed by the car and smaller FUPD. 
The intrusions for both $75 \%$ and $100 \%$ horizontal overlaps are less when the FUPD of $240 \mathrm{~mm}$ is used but it is not always the case for $50 \%$ overlap. For $50 \%$ horizontal overlap the outcome is less predictable. For the case of $280 \mathrm{~mm}$ frame FUPD offset and higher placed FUPD the frame is placed sufficiently high to not interact with the car and FUPDs behaviour is similar to one when the truck is not presented. Still, the truck cooler is at the level of the FUPD and prevents the e.a. elements to deform completely. Since the truck frame is not deformed at all for both cases it is not expected to see a big difference in intrusions even if the frame was rigid.

Acceleration was slightly more spread over displacement when the truck is present. On the other hand, the stopping distance was generally shorter and accelerations higher for these cases in comparison to idealized situations (car against e.a. FUPD only). Still better results were obtained for the deformable frame than for the rigid frame, especially for $75 \%$ horizontal overlap.

In the cases with rigid truck frame benefit advantages of having larger FUPD almost disappeared, and became only beneficial again when deformable truck frame was used. Larger FUPDs in combination with deformable truck rails gives lower intrusions, lower acceleration and less variation in these values than smaller FUPD. Smaller FUPD give less variation of intrusions for the rigid truck frame than when the larger FUPD was used in combination with the same rigid frame.

The highest force and moment resultant together with maximum displacement of free ends of e.a. elements in lateral and vertical directions showed that prescribed spring characteristics at the FUPD model were sufficient to assure stable deformation of the car. These values provide design input for the physical structures used in e.a. FUPD. Maximum deformation of e.a. elements in the impact direction was $270 \mathrm{~mm}$ and implies that available stroke of $300 \mathrm{~mm}$ could not be efficiently used. Since, the 
maximum resistance force of e.a. elements in traveling direction was reached the only reason that the available deformation distance could not be used is that the FUPD movement was restricted by integrated truck structures.

Based on the longitudinal FUPD spring forces of $284 \mathrm{kN}$ used in these simulations, future small vehicles should have compartment strengths allowing at least $350-400 \mathrm{kN}$ if these spring stiffnesses are to be considered. Current compatibility research is promoting stronger small car compartments and $350-400 \mathrm{kN}$ is the recommendation from the VC-Compat (2007) project.

\section{Conclusions}

Vehicle collisions with different e.a. FUPD geometries and configurations mounted in trucks were investigated for both vertical and horizontal offset conditions. When the FUPD is mounted on the truck with a rigid frame, the clear advantage of having larger (240 mm) FUPD disappears. A larger idealized FUPD could provide better contact and energy dissipation performance than a $120 \mathrm{~mm}$ FUPD. The main issue that arises is that when a FUPD was mounted on a truck, the frame rails and truck cooler interfered with the FUPD performance. Contacts of the car to stiffer truck structures and FUPD contact with the cooling system of the truck were observed. Small frame-FUPD offset is undesirable regardless the stiffness of the truck frames, while the advantage of having deformable truck frames increases with the FUPD-frame offset and at least 220mm is needed. The ability of deformable truck frame rails to take up energy is less influencing on crash outcome than the fact that deformable frame allows further backward movement of the FUPD than it is case for the rigid truck frame rails. In combination with deformable truck frame rails, larger FUPD shows again better performance than the smaller one. 
Acknowledgments

The authors would like to thank the Vinnova Program for Vehicle research (PFF) for enabling this work, project partners (VCC, Saab Automobile, Volvo 3P, Scania, and Autoliv Research) for their cooperation and NCAC for sharing their models with the rest of the world.

References

Delannoy P, Martin T, Castaing P. 2005. Comparative evaluation of frontal offset tests on control self and partner protection. Proceeedings of $19^{\text {th }}$ International Technical Conference on the Enhanced Safety Vehicles, paper No. 05-0010.

EEVC WG 14, European Enhanced Vehicle-safety Committee Working Group 14. 1996. Estimation of influence of rigid FUPDs on injuries to car occupants; Benefits of e.a. FUPs for trucks compared with rigid devices. Report.

European Experimental Vehicle Committee, (Now European Enhanced Vehicle-safety Committee). 1996. The validation of EEVC Frontal Impact Procedure. Proceedings of $15^{\text {th }}$ International Technical Conference on the Enhanced Safety of Vehicles. Paper 96-S3-O-28.

Forsman, L. 2002. Compatibility in Truck to Car Frontal Impacts. $7^{\text {th }}$ International Symposium on Heavy Vehicles Weights \& Dimensions. Delft ( Netherlands)

Gwehenberger J, Bende J, Knight I, Klootwijk C. 2003. Collection of Existing Indepth Accident Cases and Prediction of Benefit on Having Front and Rear Underrun Protection. VC-Compat. Task 2.7/2.8. European Commission Project $\mathrm{N}^{\circ}$ GRD2/2001/50083.

Krusper A, Thomson R. 2008. Compatibility between Heavy Goods Vehicles and Passenger Cars: Structural Interaction Analysis and In-depth Accident Analysis. Proceedings of International Conference on Heavy Vehicles, Paper $\mathrm{N}^{\circ} 25$. Paris (France) 
Krusper A, Thomson R. 2010. Energy-absorbing FUPDs and their interaction with fronts of passenger cars. International Journal of Crashworthiness, 15: 6, 635 647

Krusper A, Thomson R. 2010. Crash performance of front underrun protective device with a passenger car under different crash configurations - Results of finite element method based simulations. Department of Applied Mechanics. Chalmers University of Technology.Research report 2010:07. Gothenburg (Sweden).

Livermore Software Technology Corp. 2007. LS-DYNA® keyword user’s manualversion 971.

[NCAC] National Crash Analysis Center [Internet]. 2001 Ford Taurus; [downloaded 2007 May 22]. Available from: http://www.ncac.gwu.edu/.

[NHTSA] National Highway Traffic Safety Administration. 1998. Trends in large truck crashes. National Technical Information Services. DOT-HS-808-690. Springfield. Virginia (USA).

Rechnitzer G. 1993. Truck involved crash study, fatal and injury crashes of cars and other road users with the front and sides of heavy vehicles. A research project for VIC ROADS Road Safety Division. Report $N^{\circ} 35$.

Schram R, Leneman F J W, de Coo P J A, van der Zweep C D. 2006. Report detailing reference baselines to evaluate underrun guard test procedure(s) to be proposed in WP9. Improvement of vehicle crash compatibility through the development of crash test procedures (VC-Compat). Deliverable $\mathrm{N}^{\circ}$ D14. Project $\mathrm{N}^{\circ}$ : GRD22001-50083.

Schram R, Leneman F J W, van der Zweep C D, Wismans J S H M, Witteman W J. 2006. Assessment criteria for assessing energy-absorbing front underrun protection on trucks. International Journal of Crashworthiness, 11: 6, 597 604. 
Schäfer R, Schepers A, Assing K, otte D, Nehmzow J, Faerber E, Adalian C, Cocoual M, Zac R, Césari D, Aparicio F, Páez F J, van Kampen B. 1999. WP2 Accident Analysis. Report for the European Commission DGVII. Volume 3. Contract $\mathrm{N}^{\circ}$ : R0-97-SC.1064

Thomas GE. 2005. Compatibility and structural interaction in passenger vehicle collisions. protection on trucks. Faculty of Engineering, RMIT University. Ph.D. Thesis. Melbourne (Australia).

Thomson R, Krusper A, Avramov A, Rachid K. 2008. The role of vehicle design on structural interaction. International Crashworthiness Conference. Kyoto (Japan).

[VC-Compat] Vehicle Crash Compatibility]. 2007. Vehicle Crash Compatibility through the Development of Crash Test Procedures. Final Technical Report. European Commission Project N: GRD2/2001/50083.

Table 1. Taurus against e.a. FUPD (speed $75 \mathrm{~km} / \mathrm{h}$ ) - performed in previous work (Krusper and Thomson 2010)

Table 2. Taurus against truck with rigid frame rails (speed $75 \mathrm{~km} / \mathrm{h}$ )

Table 3. Taurus against truck with deformable frame rails (speed $75 \mathrm{~km} / \mathrm{h}$ )

Table 4. Maximum force and moment resultants at e.a. elements and maximum displacement of free ends of e.a. elements 
Table 1. Taurus against e.a FUPD (speed $75 \mathrm{~km} / \mathrm{h}$ )- ) performed in previous work (Krusper and Thomson 2010)

\begin{tabular}{|c|c|c|c|c|c|c|c|c|c|}
\hline \multirow[t]{2}{*}{ No. } & \multirow{2}{*}{$\begin{array}{l}\text { FUPD } \\
\text { height }\end{array}$} & \multicolumn{2}{|c|}{ Overlap } & \multirow{2}{*}{$\begin{array}{c}\text { FUPD } \\
\text { position } \\
\text { relative to } \\
\text { car long.. }\end{array}$} & \multirow[t]{2}{*}{ No. } & \multirow{2}{*}{$\begin{array}{l}\text { FUPD } \\
\text { height } \\
{[\mathrm{mm}]}\end{array}$} & \multicolumn{2}{|c|}{ Overlap } & \multirow{2}{*}{$\begin{array}{c}\text { FUPD } \\
\text { position } \\
\text { relative to } \\
\text { car long. }\end{array}$} \\
\hline & & Horizontal & Vertical & & & & Horizontal & Vertical & \\
\hline 1 & 120 & 100 & 50 & Higher & 10 & 240 & 100 & 50 & Higher \\
\hline 2 & 120 & 100 & 100 & - & 11 & 240 & 100 & 100 & - \\
\hline 3 & 120 & 100 & 50 & Lower & 12 & 240 & 100 & 50 & Lower \\
\hline 4 & 120 & 75 & 50 & Higher & 13 & 240 & 75 & 50 & Higher \\
\hline 5 & 120 & 75 & 100 & - & 14 & 240 & 75 & 100 & - \\
\hline 6 & 120 & 75 & 50 & Lower & 15 & 240 & 75 & 50 & Lower \\
\hline 7 & 120 & 50 & 50 & Higher & 16 & 240 & 50 & 50 & Higher \\
\hline 8 & 120 & 50 & 100 & - & 17 & 240 & 50 & 100 & - \\
\hline 9 & 120 & 50 & 50 & Lower & 18 & 240 & 50 & 50 & Lower \\
\hline
\end{tabular}

Table 2. Taurus against truck with rigid frame rails (speed $75 \mathrm{~km} / \mathrm{h}$ )

\begin{tabular}{|c|c|c|c|c|c|c|c|c|c|c|c|}
\hline \multirow[t]{2}{*}{ No. } & \multirow[b]{2}{*}{$\begin{array}{l}\text { Frame } \\
\text { rails - } \\
\text { FUPD } \\
\text { offset } \\
{[\mathrm{mm}]}\end{array}$} & \multirow{2}{*}{$\begin{array}{c}\text { FUPD } \\
\text { height } \\
{[\mathrm{mm}]}\end{array}$} & \multicolumn{2}{|c|}{ Overlap } & \multirow[b]{2}{*}{$\begin{array}{l}\text { FUPD } \\
\text { position } \\
\text { relative } \\
\text { to car } \\
\text { long. }\end{array}$} & \multirow[t]{2}{*}{ No. } & \multirow[b]{2}{*}{$\begin{array}{l}\text { Frame } \\
\text { rails - } \\
\text { FUPD } \\
\text { offset } \\
{[\mathrm{mm}]}\end{array}$} & \multirow{2}{*}{$\begin{array}{l}\text { FUPD } \\
\text { height } \\
{[\mathrm{mm}]}\end{array}$} & \multicolumn{2}{|c|}{ Overlap } & \multirow[b]{2}{*}{$\begin{array}{l}\text { FUPD } \\
\text { position } \\
\text { relative } \\
\text { to car } \\
\text { long. }\end{array}$} \\
\hline & & & $\begin{array}{c}\text { Horizontal } \\
{[\%]}\end{array}$ & $\begin{array}{c}\text { Vertical } \\
{[\%]}\end{array}$ & & & & & $\begin{array}{c}\text { Horizontal } \\
{[\%]}\end{array}$ & $\begin{array}{c}\text { Vertical } \\
{[\%]}\end{array}$ & \\
\hline 1 & 160 & 120 & 100 & 100 & - & 12 & 220 & 120 & 75 & 50 & Lower \\
\hline 2 & 160 & 120 & 75 & 100 & - & 13 & 220 & 240 & 75 & 50 & Higher \\
\hline 3 & 160 & 120 & 75 & 50 & Lower & 14 & 220 & 240 & 75 & 100 & - \\
\hline 4 & 160 & 120 & 50 & 100 & - & 15 & 220 & 240 & 75 & 50 & Lower \\
\hline 5 & 160 & 120 & 50 & 50 & Lower & 16 & 280 & 120 & 75 & 100 & - \\
\hline 6 & 160 & 240 & 100 & 100 & - & 17 & 280 & 120 & 75 & 50 & Lower \\
\hline 7 & 160 & 240 & 75 & 100 & - & 18 & 280 & 120 & 50 & 50 & Lower \\
\hline 8 & 160 & 240 & 75 & 50 & Lower & 19 & 280 & 240 & 75 & 100 & - \\
\hline 9 & 160 & 240 & 50 & 100 & - & 20 & 280 & 240 & 75 & 50 & Lower \\
\hline 10 & 160 & 240 & 50 & 50 & Lower & 21 & 280 & 240 & 50 & 50 & Lower \\
\hline 11 & 220 & 120 & 75 & 100 & - & & & & & & \\
\hline
\end{tabular}

Table 3. Taurus against truck with deformable frame rails (speed $75 \mathrm{~km} / \mathrm{h}$ )

\begin{tabular}{|c|c|c|c|c|c|c|c|c|c|c|c|}
\hline \multirow[t]{2}{*}{ No. } & \multirow[b]{2}{*}{$\begin{array}{l}\text { Frame } \\
\text { rails - } \\
\text { FUPD } \\
\text { offset } \\
{[\mathrm{mm}]} \\
\end{array}$} & \multirow{2}{*}{$\begin{array}{l}\text { FUPD } \\
\text { height } \\
{[\mathrm{mm}]}\end{array}$} & \multicolumn{2}{|c|}{ Overlap } & \multirow[b]{2}{*}{$\begin{array}{l}\text { FUPD } \\
\text { position } \\
\text { relative } \\
\text { to car } \\
\text { long } \\
\end{array}$} & \multirow[t]{2}{*}{ No. } & \multirow[b]{2}{*}{$\begin{array}{l}\text { Frame } \\
\text { rails - } \\
\text { FUPD } \\
\text { offset } \\
{[\mathrm{mm}]} \\
\end{array}$} & \multirow{2}{*}{$\begin{array}{c}\text { FUPD } \\
\text { height } \\
{[\mathrm{mm}]}\end{array}$} & \multicolumn{2}{|c|}{ Overlap } & \multirow[b]{2}{*}{$\begin{array}{l}\text { FUPD } \\
\text { position } \\
\text { relative } \\
\text { to car } \\
\text { long. }\end{array}$} \\
\hline & & & $\begin{array}{c}\text { Horizontal } \\
{[\%]}\end{array}$ & $\begin{array}{c}\text { Vertical } \\
{[\%]}\end{array}$ & & & & & $\begin{array}{c}\text { Horizontal } \\
{[\%]}\end{array}$ & $\begin{array}{c}\text { Vertical } \\
{[\%]}\end{array}$ & \\
\hline 1 & 160 & 120 & 100 & 100 & - & 14 & 220 & 120 & 50 & 50 & Lower \\
\hline 2 & 160 & 120 & 75 & 100 & - & 15 & 220 & 240 & 100 & 50 & Higher \\
\hline 3 & 160 & 120 & 75 & 50 & Lower & 16 & 220 & 240 & 75 & 50 & Higher \\
\hline 4 & 160 & 120 & 50 & 100 & - & 17 & 220 & 240 & 75 & 100 & - \\
\hline 5 & 160 & 120 & 50 & 50 & Lower & 18 & 220 & 240 & 75 & 50 & Lower \\
\hline 6 & 160 & 240 & 100 & 100 & - & 19 & 220 & 240 & 50 & 50 & Higher \\
\hline 7 & 160 & 240 & 75 & 100 & & 20 & 280 & 120 & 75 & 50 & Lower \\
\hline 8 & 160 & 240 & 75 & 50 & Lower & 21 & 280 & 120 & 50 & 50 & Higher \\
\hline 9 & 160 & 240 & 50 & 100 & - & 22 & 280 & 120 & 50 & 50 & Lower \\
\hline 10 & 160 & 240 & 50 & 50 & Lower & 23 & 280 & 240 & 100 & 100 & - \\
\hline 11 & 220 & 120 & 100 & 100 & - & 24 & 280 & 240 & 75 & 100 & - \\
\hline 12 & 220 & 120 & 75 & 100 & - & 25 & 280 & 240 & 50 & 50 & Higher \\
\hline 13 & 220 & 120 & 75 & 50 & Lower & 26 & 280 & 240 & 50 & 50 & Lower \\
\hline
\end{tabular}


Table 4. Maximum force and moment resultants at e.a. elements and maximum displacement of free ends of e.a. elements

\begin{tabular}{lcccl}
\hline & & $\begin{array}{c}\text { FUPD } \\
\text { side }\end{array}$ & Value & Simulation \\
& & Left & 284 & FUPD120 H75\% V50\%Lower, Offset 220mm, TrR \\
\hline Max force & Fr & Left & 121 & FUPD120 H75\% V50\%Lower, Offset 220mm, TrR \\
resultant[kN] & Fs & Right & 96 & FUPD120 H75\% V50\%Lower, Offset 220mm, TrD \\
\hline Max moment & Fr & Left & 6 & FUPD120 H75\% V50\%Lower, Offset 220mm, TrR \\
resultant & Ms & Right & 17 & FUPD120 H75\% V50\%Lower, Offset 220mm, TrR \\
{$[\mathrm{kNm}]$} & $\mathrm{Mt}$ & Right & 11 & FUPD240 H50\% V50\%Higher, Offset 220mm, TrD \\
\hline Max & $\mathrm{X}$ & Left & 270 & FUPD240 H50\% V50\%Higher, Offset 280mm, TrD \\
displacement & $\mathrm{Y}$ & Right & 38 & FUPD120 H75\% V50Lower, Offset 220mm, TrD \\
{$[$ mm $]$} & $\mathrm{Z}$ & Right & 33 & FUPD240 H50\% V50\%Higher, Offset 220mm, TrD \\
\hline
\end{tabular}

Figure 1. Acceleration vs time (left) and rigid wall force vs displacement from rigid barrier test of 22 European vehicles were used as a reference for modification of Taurus model used in the simulations.

Figure 2. FE models of passenger cars.

Figure 3. Model of simplified e.a. FUPD: (a) e.a. FUPD consisting of FUPD cross-beam and FUPD e.a. elements (modelled as springs) and (b) force/moment vs displacement/rotation characteristics of the e.a. elements (springs).

Figure 4. Truck model with incorporated e.a. FUPD.

Figure 5. Points at firewall where intrusions are measured.

Figure 6. Calculated energies for two simulations

Figure 7. Vehicle deformation in three different simulation cases.

Figure 8. Intrusions registered for car- e.a. FUPD (left column) and car-rigid frame truck (right column) impacts. The upper row refers to dashboard intrusions and the lower one to footwell intrusions.

Figure 9. Acceleration vs. displacement curve for full vertical overlap and different horizontal overlaps for car-FUPD (left column) and car-rigid truck.

Figure 10. An energy absorption for car-FUPD and car-rigid frame truck impacts (160 $\mathrm{mm}$ frame-FUPD offset) under $75 \%$ horizontal and $100 \%$ vertical overlaps.

Figure 11. Calculated intrusions of the dashboard and footwell of the car impacting the truck with rigid frame rails

Figure 12. Calculated intrusions of the dashboard and footwell of the car impacting the truck with deformable frame rails 
Figure 13. Energy absorption (left) and acceleration - vs. displacement curves (right) for car-rigid frame truck (TrR ), car-deformable frame truck (TrD) and car-FUPD impacts when FUPD of $240 \mathrm{~mm}$ is used. The horizontal overlap is $50 \%$ and vertical overlap is $50 \%$ when the FUPD is placed lower relative to the longitudinals.

Figure 14. Acceleration vs displacement curves for the car impacting the truck with rigid frame rails under different horizontal and vertical overlaps.

Figure 15. Acceleration vs displacement curves for the car impacting the truck with deformable frame rails under different horizontal and vertical overlaps.

Figure 16. Comparison between energy distributions for FUPD120 and FUPD240 mounted on trucks with rigid or deformable frame rails.

Figure 17. Comparison of energy distributions for different offsets for a FUPD of 120 $\mathrm{mm}$ cross-section $\mathrm{mm}$ for rigid and deformable truck frame rails.

Figure 18. Comparison of energy distributions for different offsets for a FUPD of 240 $\mathrm{mm}$ cross-section $\mathrm{mm}$ for rigid and deformable truck frame rails.

Figure 19. . Frontal forces in $56 \mathrm{~km} / \mathrm{h}$ impacts for rigid wall and $75 \%$ horizontal overlap car-truck/FUPD collisions.
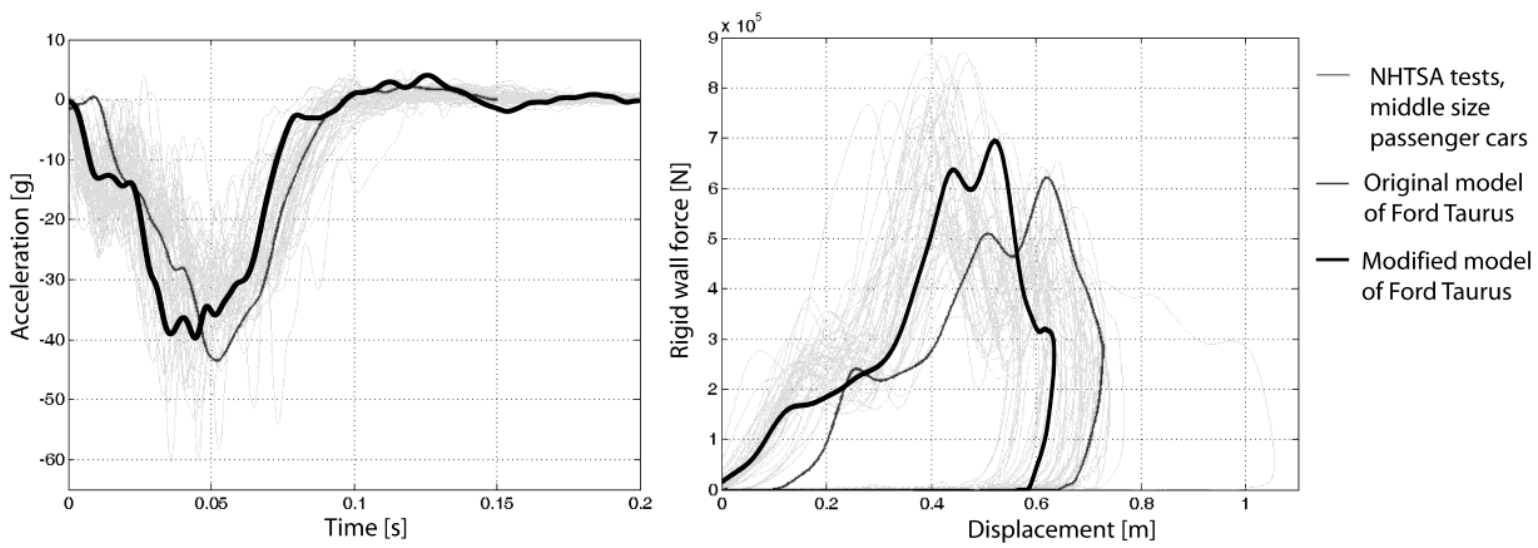

Figure 1 


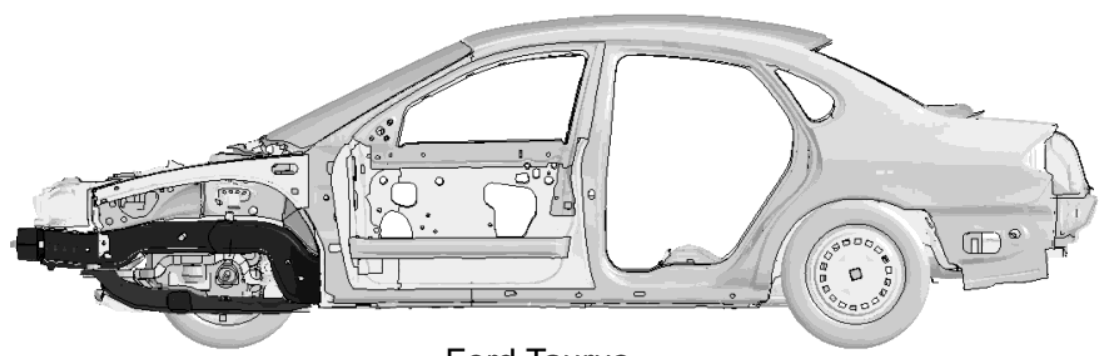

Ford Taurus

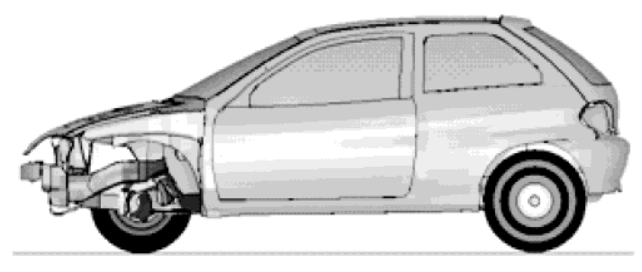

Geo Metro

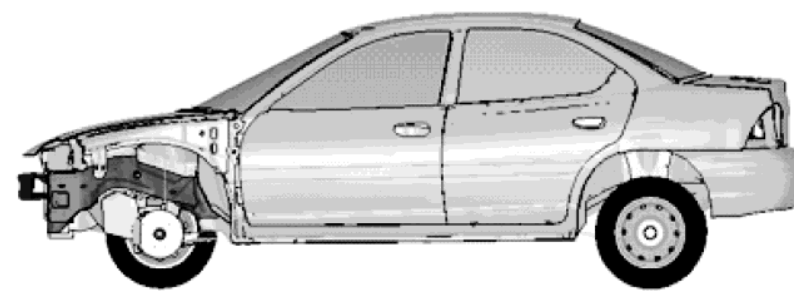

Dodge Neon

Figure 2
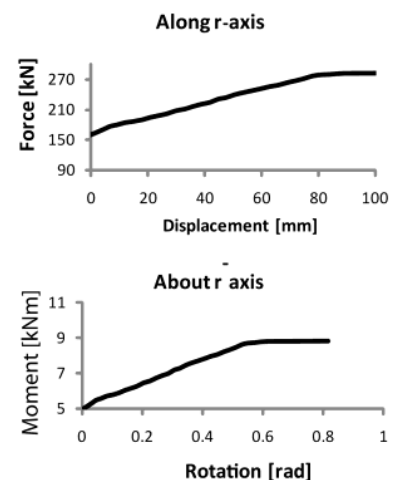

Rotation [rad]
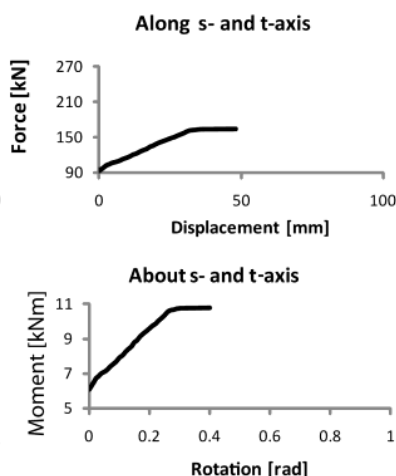

b)
Global coord.

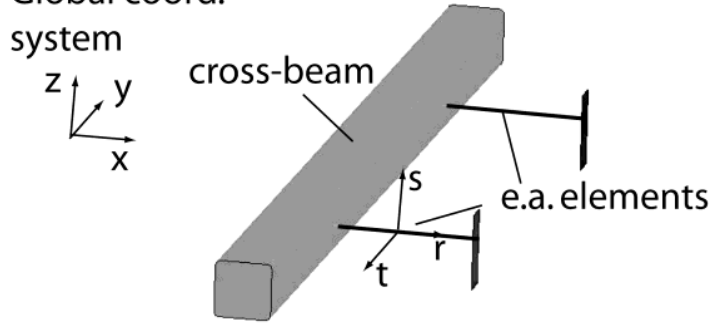

a)

Figure 3 


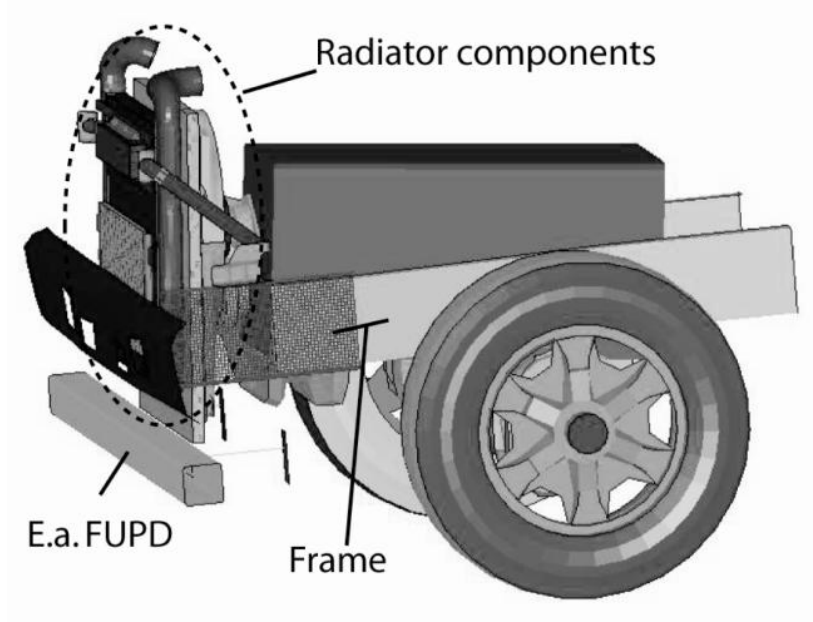

Figure 4

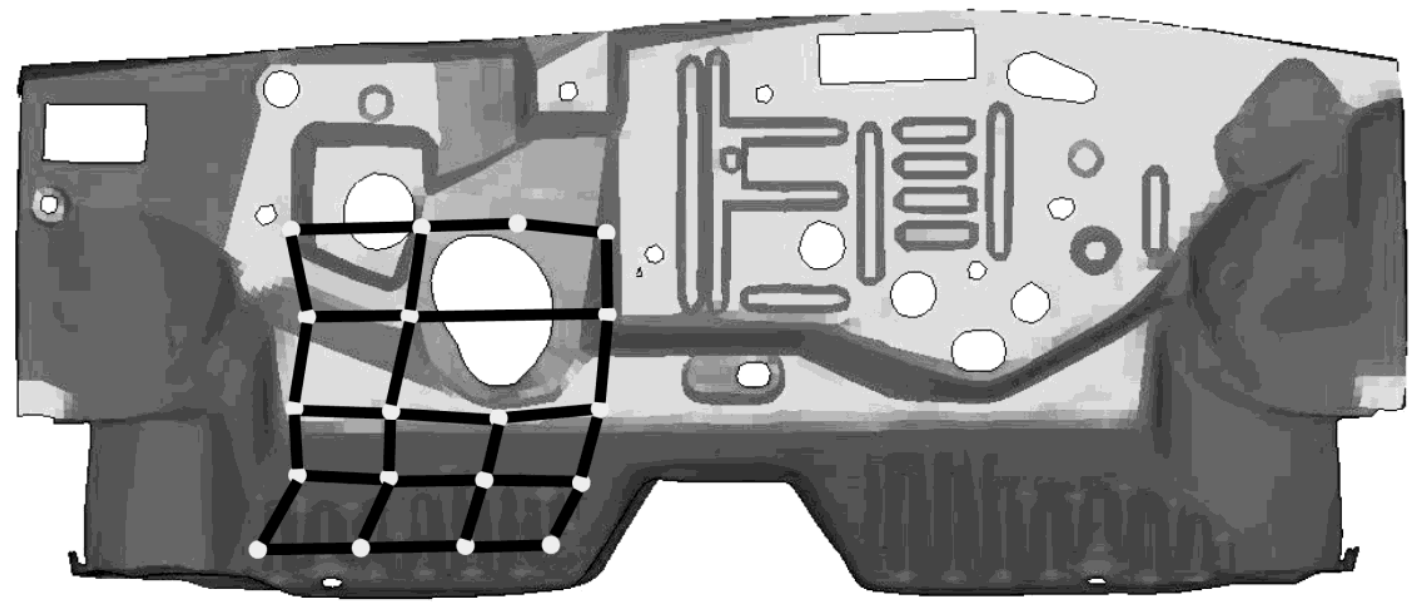

Figure 5 
Car (Taurus) against truck with rigid frame rails - offset $160 \mathrm{~mm}$

$100 \%$ h. overlap, $100 \%$ v. overlap

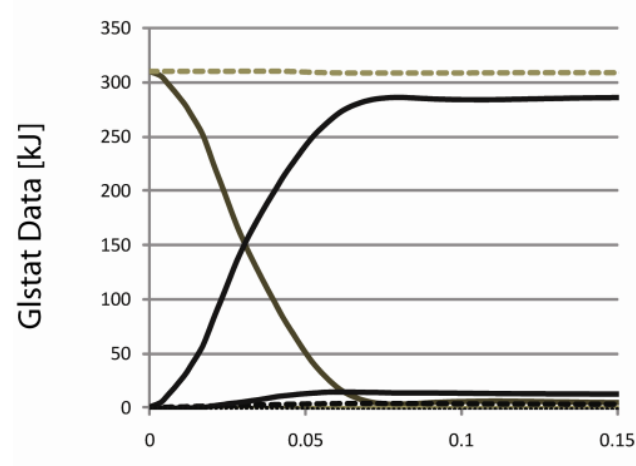

Car (Taurus) against truck with

deformable frame rails - offset $220 \mathrm{~mm}$

$75 \%$ h. overlap, $100 \%$ v. overlap

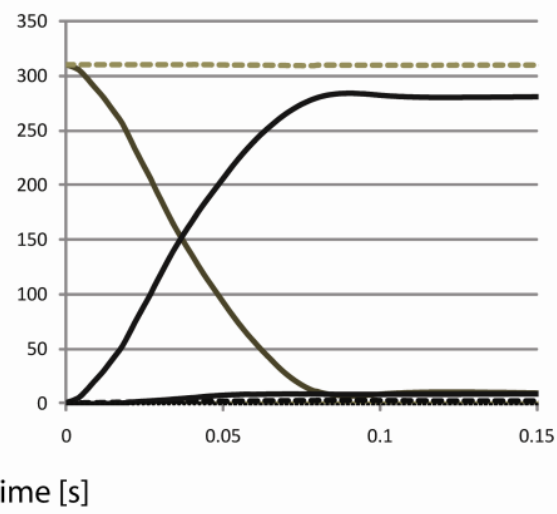

Kinetic Ene

Internal En€

$-\infty$ Total Energ!

- Spring \& Da

- - Hourglass E

- Sliding Ener

......... External Wc

Figure 6

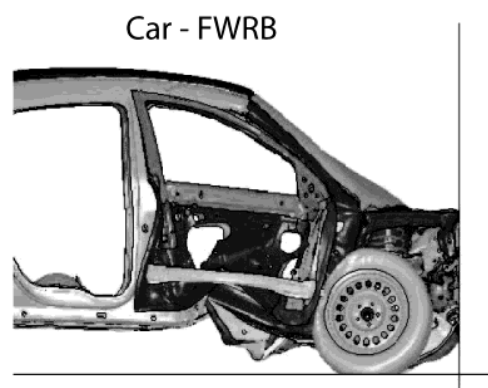

Car - e.a.FUPD

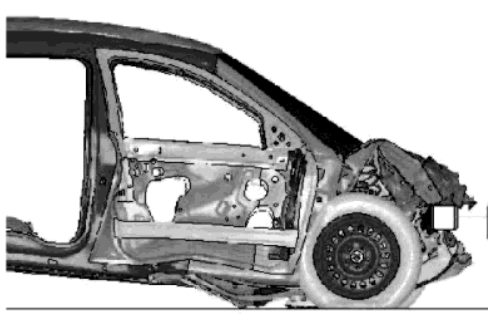

Car - Rigid frame truck (offset 160mm)

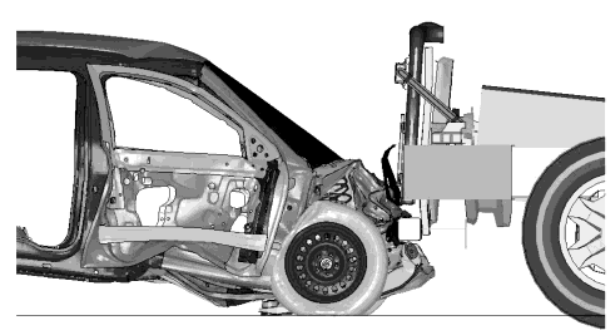

Figure 7 


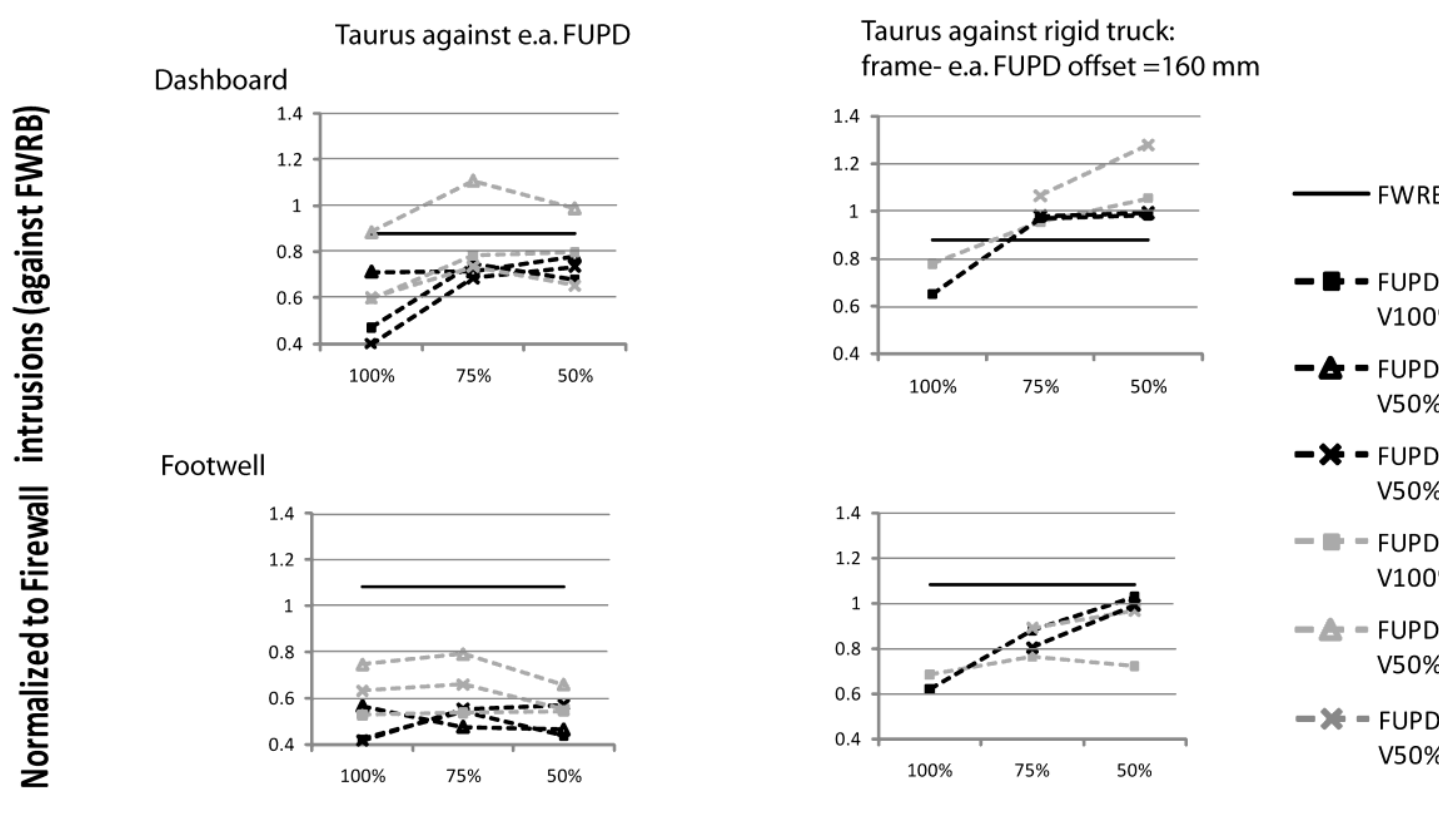

Horizontal overlap

Figure 8

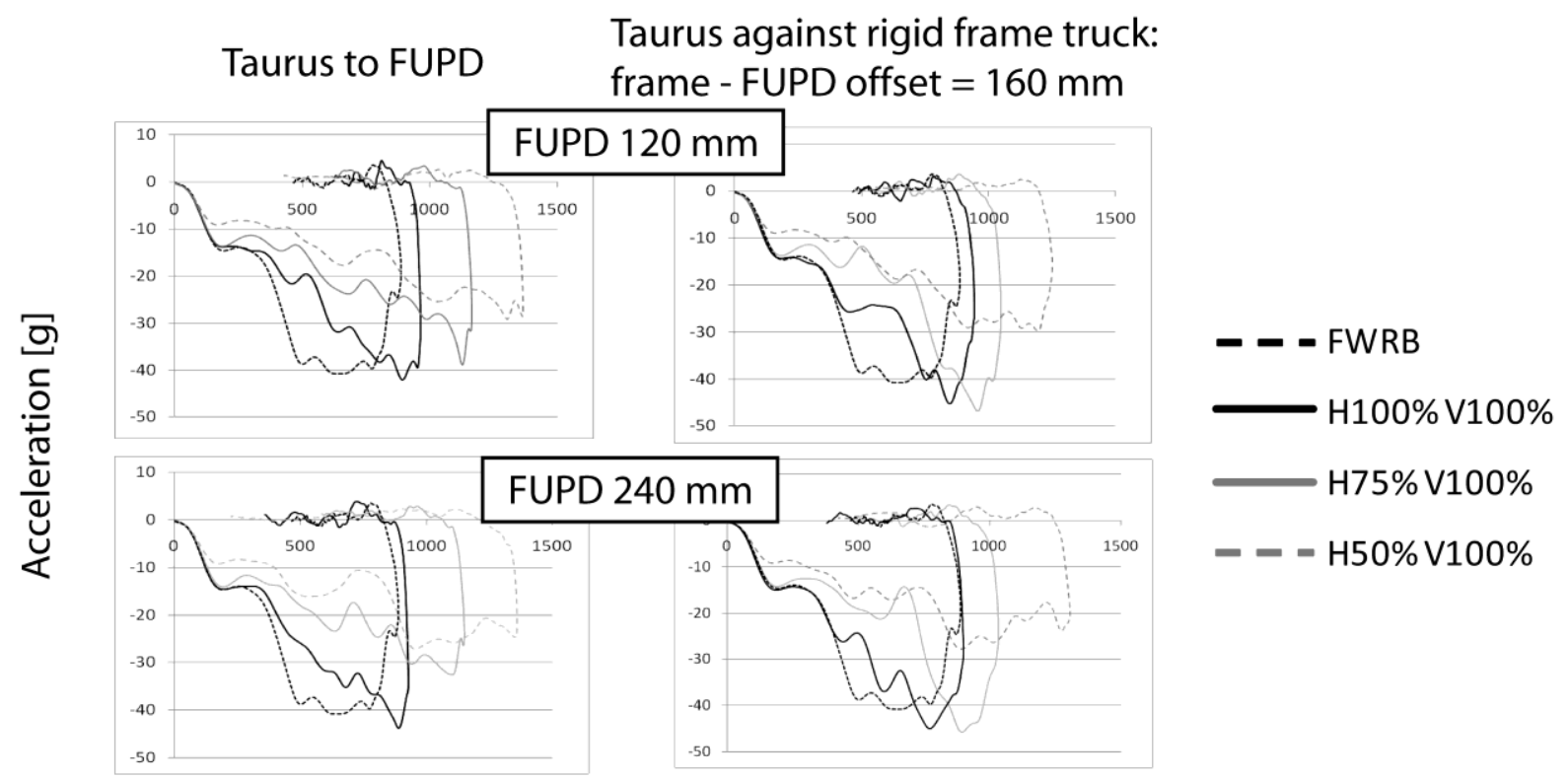

Figure 9

Displacement [mm ] 
$75 \%$ h. overlap, $100 \%$ v. Overlap, Offset $160 \mathrm{~mm}$

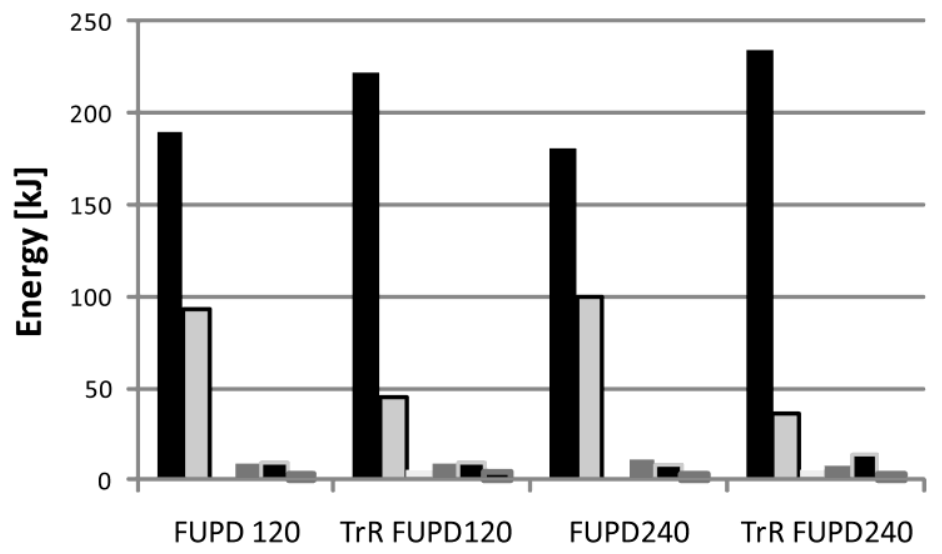

- Car abs.

$\square$ FUPD abs.

Truck abs.

Residual

- Sliding

- Hourglass

Figure 10

Rigid truck frame rails

Dashboard

Offset $160 \mathrm{~mm}$

Offset $220 \mathrm{~mm}$

Offset $280 \mathrm{~mm}$
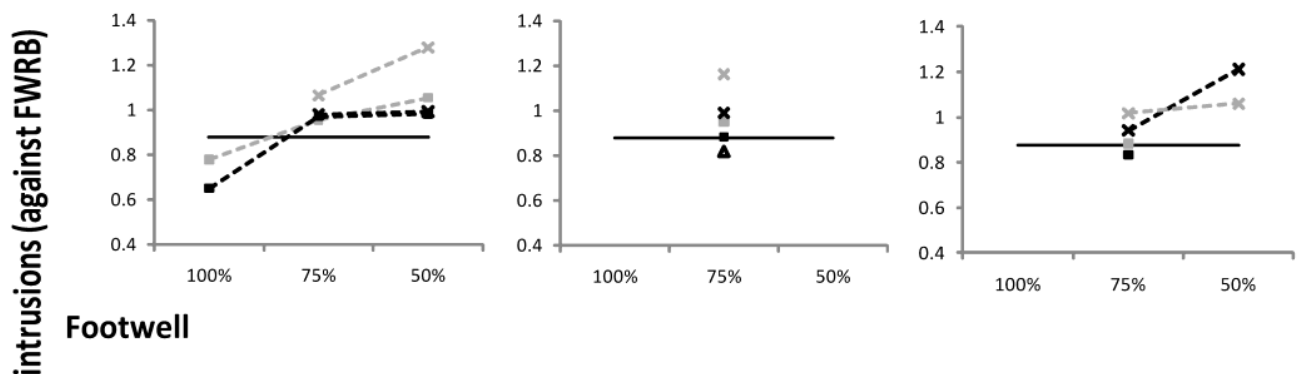

- FWRB

- - FUPD1

- - - FUPD2

$-x-$ FUPD 1

V50\%L
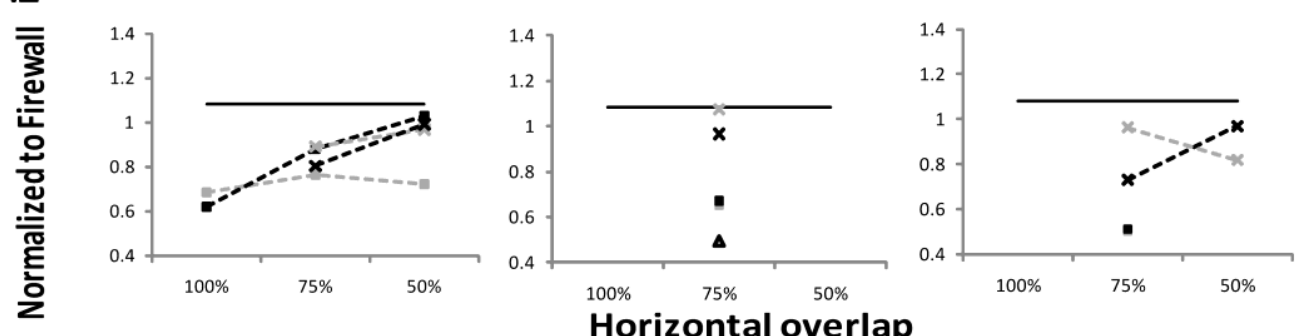

$-x-$ FUPD2 $\mathrm{V} 50 \% \mathrm{~L}$

$-\Delta=$ FUPD1 V50\%

$-\Delta-$ FUPD2

V $50 \%$ r

Figure 11 
Deformable truck frame rails

Dashboard

Offset $160 \mathrm{~mm}$

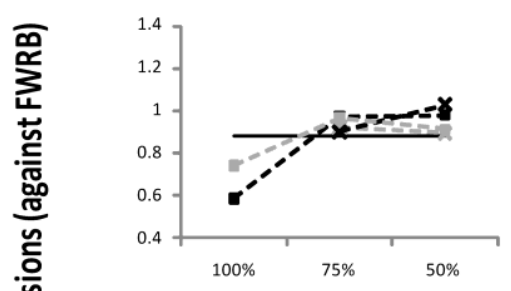

Footwell
Offset $220 \mathrm{~mm}$
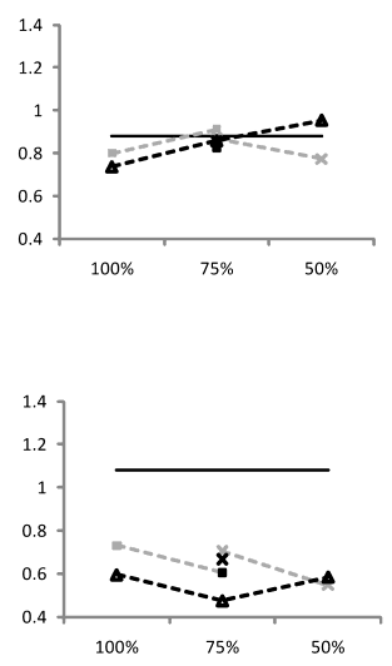

Horizontal overlap

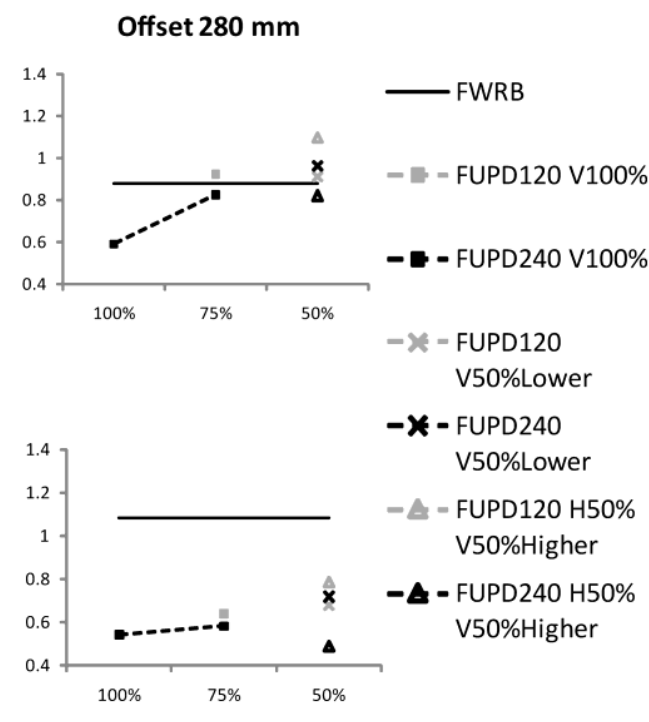

Figure 12

H50\% V50\%Lower, Offset 280mm
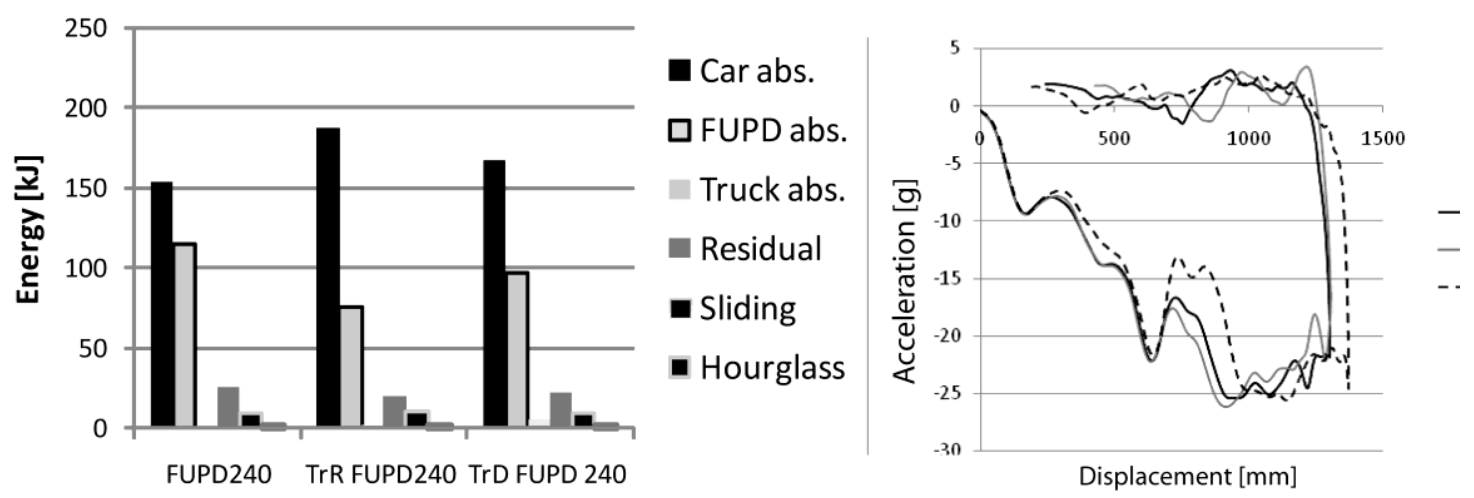

Figure 13 
Rigid truck frame

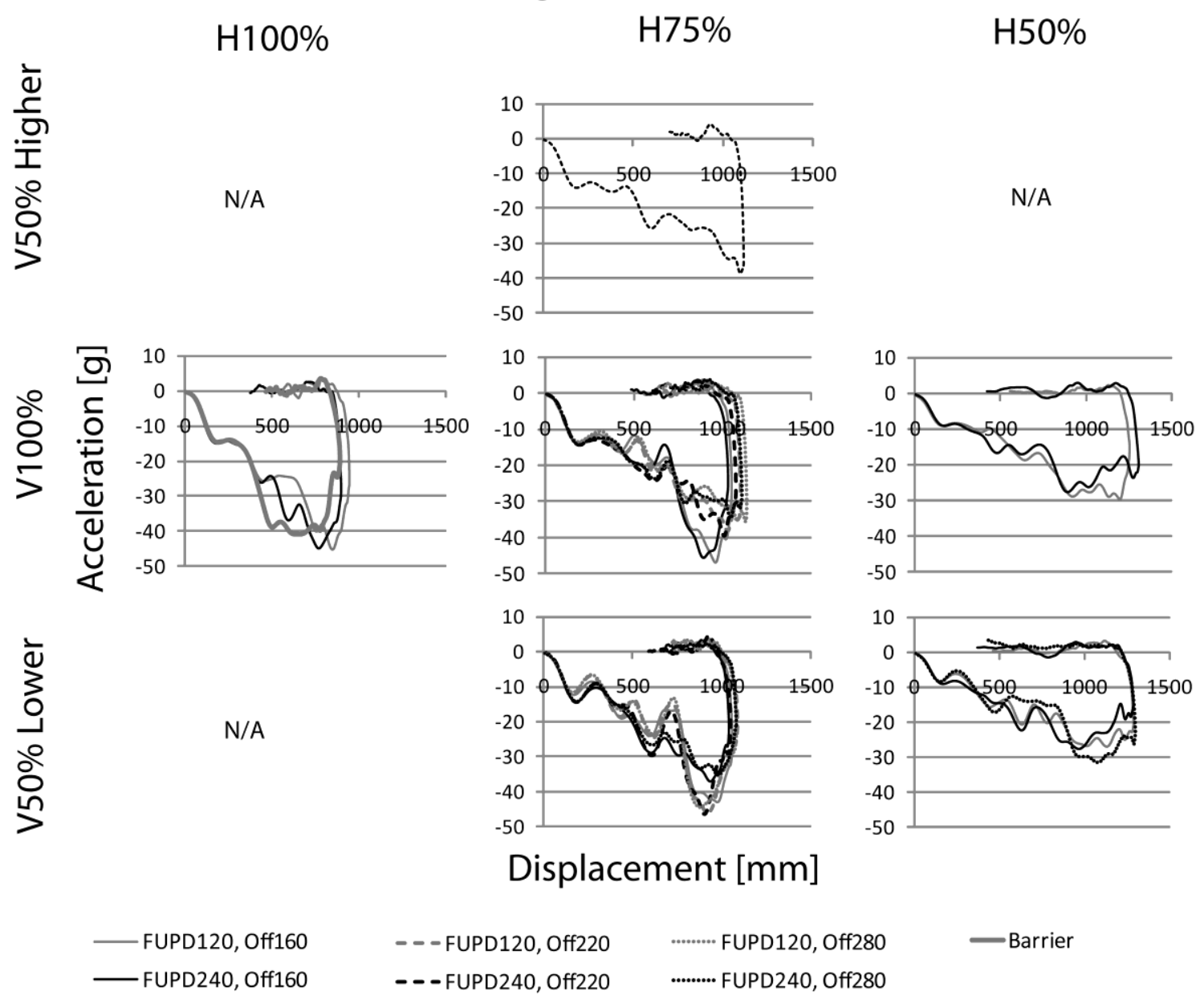

Figure 14 
Deformable truck frame rails

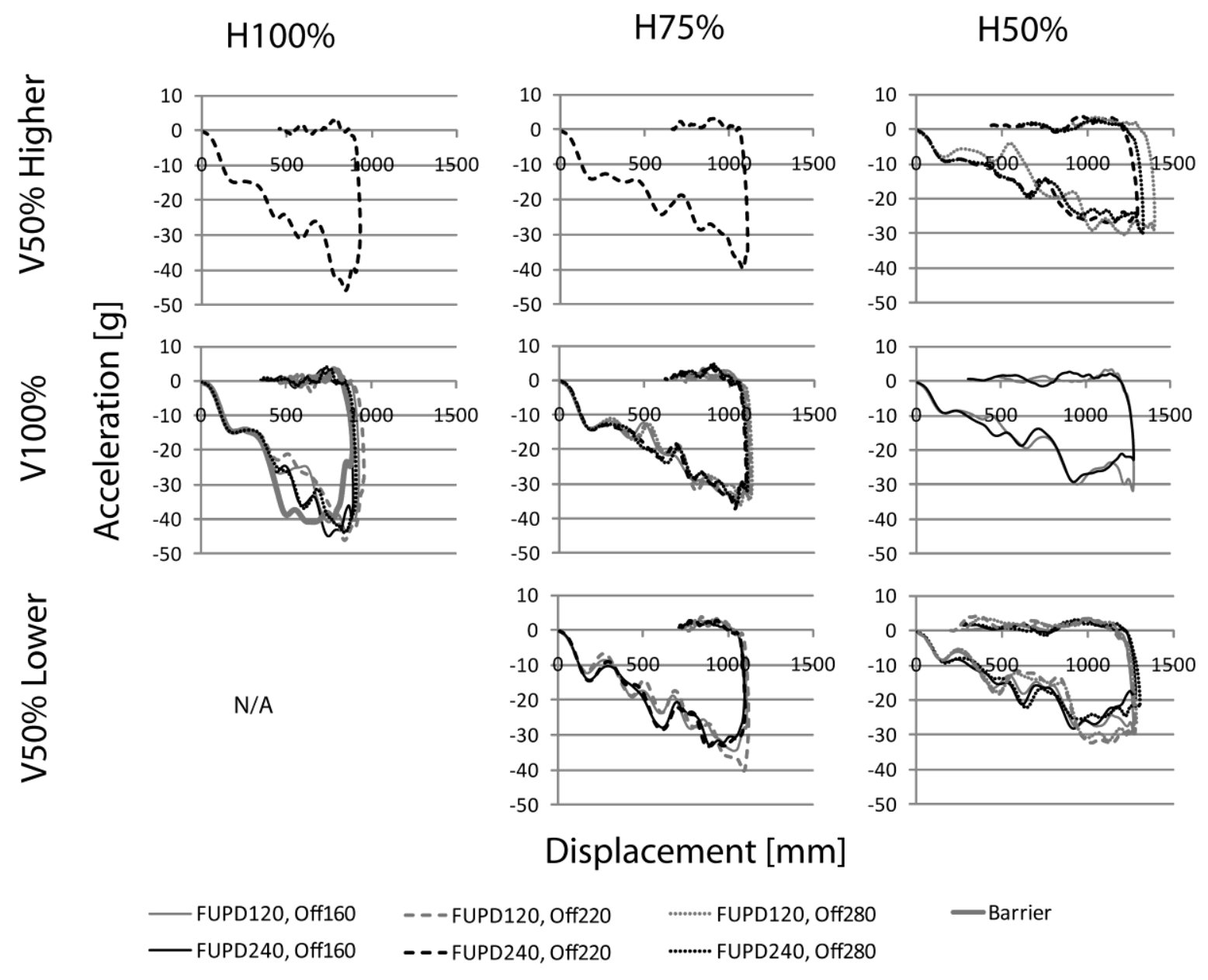

Figure 15

$50 \%$ h. overlap, 50\% Lower v. overlap, Offset $280 \mathrm{~mm}$

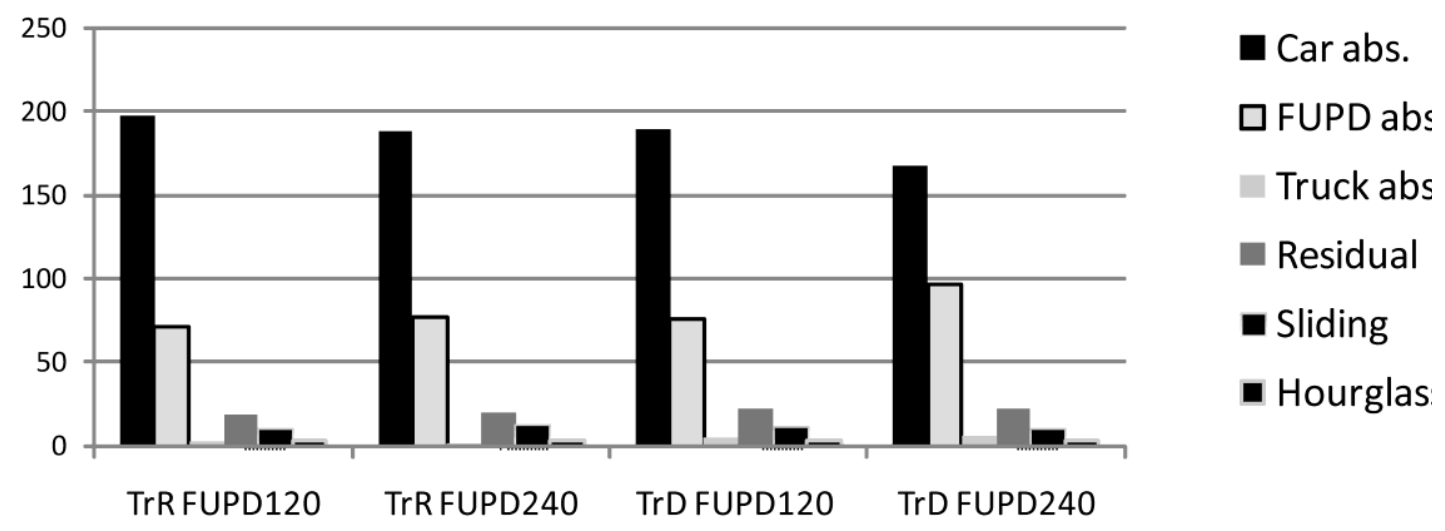

Figure 16 
FUPD 120, 75\% h. overlap, 100\% v. overlap

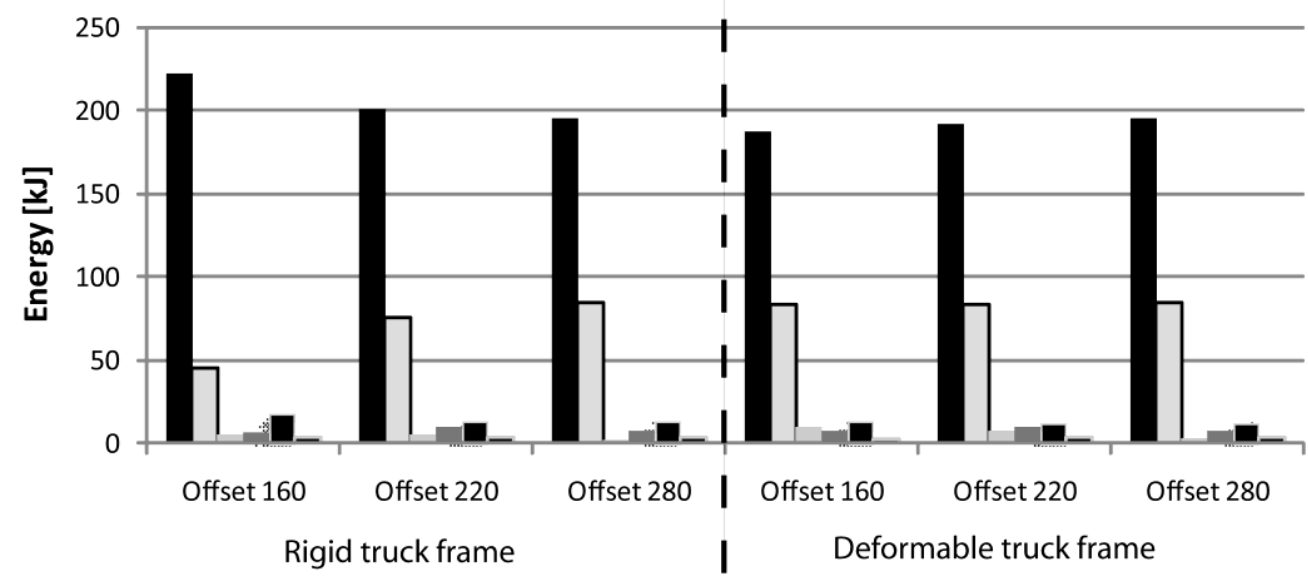

- Car abs.

$\square$ FUPD abs.

Truck abs.

nesidual

- Sliding

- Hourglass en.

Figure 17

FUPD $240,75 \%$ h. overlap, $100 \%$ v. overlap

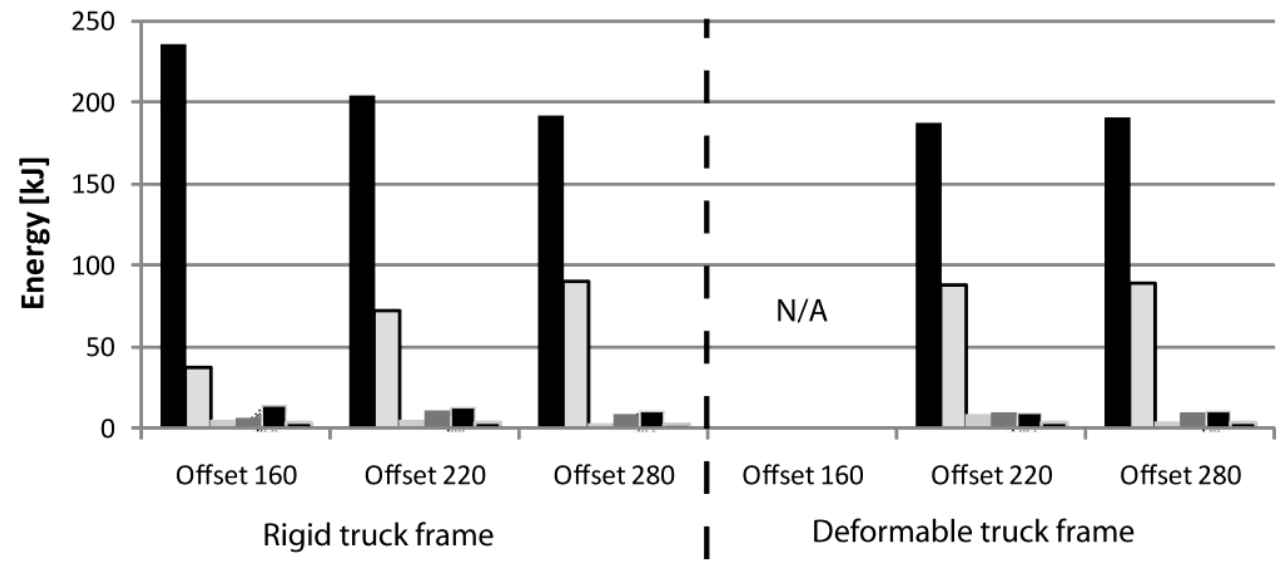

- Car abs.

$\square$ FUPD abs.

Truck abs.

- Residual

- Sliding

- Hourglass en.

Figure 18 


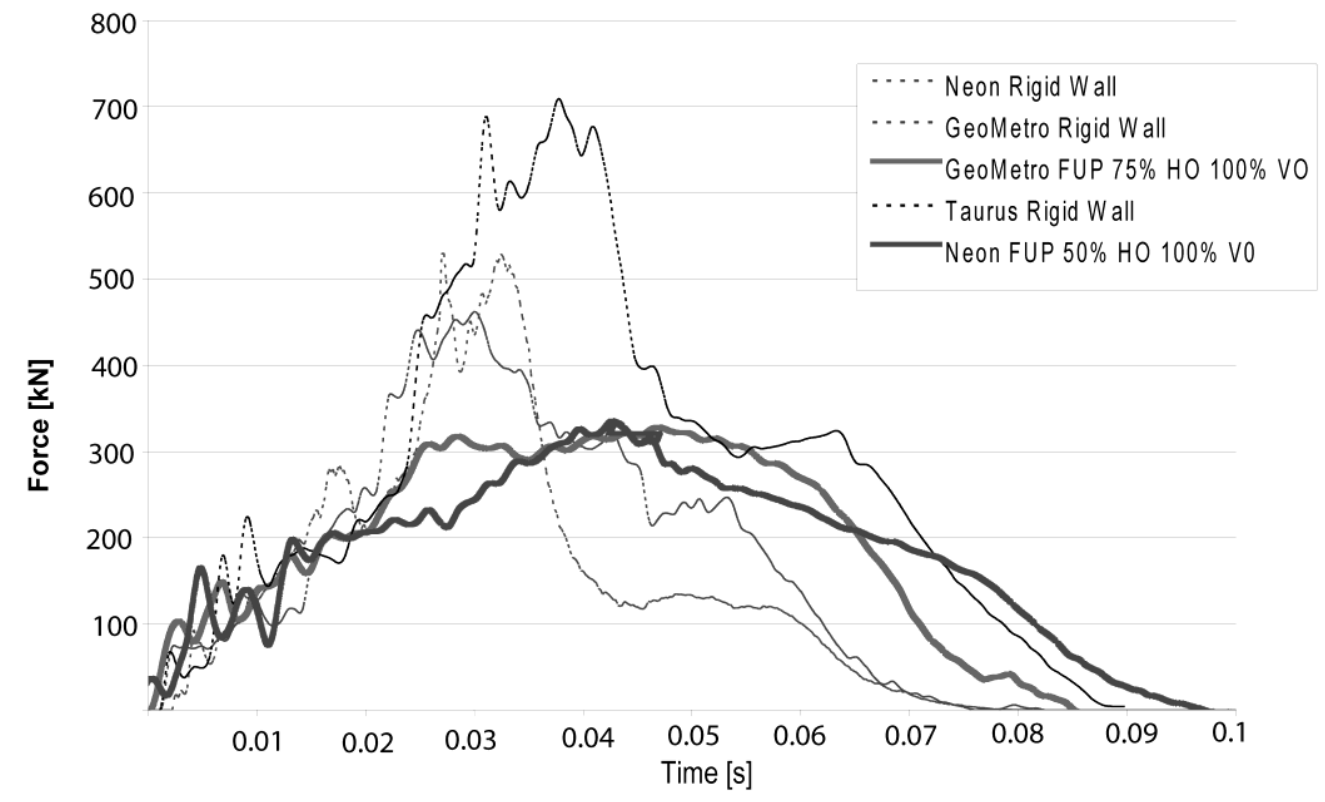

Figure 19 